\title{
TRIAGEM VIRTUAL PARA IDENTIFICAÇÃO DE INIBIDORES DA DIHIDROPTEROATO SINTASE DO MYCOBACTERIUM TUBERCULOSIS
}

\author{
THIAGO FERREIRA NASCIMENTO MIRANDA ${ }^{1}$; MANOELITO COELHO \\ DOS SANTOS JUNIOR ${ }^{2}$ \\ 1. Bolsista FAPESB, Graduando em Farmácia, Universidade Estadual de Feira de Santana, e-mail: \\ tigo mira@yahoo.com.br \\ 2. Orientador, Departamento de Saúde, Universidade Estadual de Feira de Santana, e-mail: \\ mc2500@gmail.com.
}

PALAVRAS-CHAVE: Mycobacterium tuberculosis, triagem virtual, Dihidropteroato
sintase.

\section{INTRODUÇÃO}

A tuberculose (TB) continua sendo mundialmente um importante problema de saúde, exigindo o desenvolvimento de estratégias para o seu controle, considerando aspectos humanitários, econômicos e de saúde pública.. Sendo considerada a doença infecciosa com o maior numero de óbito em 2014, estimado em 1,5 milhões de pessoas (WHO, 2015). Levando em consideração a necessidade de novos fármacos e o desinteresse da indústria farmacêutica. Baseando-se nestes fatos, a enzima chave dihidropteroato sintase - DHPS (EC 2.5.1.15) com código no Protein Data Bank (PDB) $1 E Y E$ constitui um bom alvo, pois a mesma é responsável pela etapa limitante da biossíntese DHPS sendo essencial para a síntese de novos de folatos em procariotas, eucariotas inferiores, e em plantas, mas está ausente em mamífero.

\section{METODOLOGIA}

A etapa inicial para a triagem virtual é a seleção do conjunto de estruturas que compõem o banco de dados, assim, foi utilizado o $\mathrm{ZINC}^{15}$, que é um dos maiores acervos mundiais de estruturas químicas para estudos de pesquisa e desenvolvimento de novos fármacos. Sendo o banco BIOGENIC incluso no $\mathrm{ZINC}^{15}$ escolhido para o acoplamento (IRWIN et al., 2015).

O acoplamento molecular foi realizado pelo programa DOCK 6.7 e seus programas acessórios (EWING et al., 2001). A avaliação dos parâmetros estabelecidos foi realizada através da capacidade do DOCK $6.7 \mathrm{em}$ reposicionar o ligante cristalográfico no sítio ortostérico da enzima, para isso foi calculado o valor de RMSD (Root Mean Square Deviation) entre a pose gerada pelo acoplamento molecular e a de origem. (BROZELL et al, 2012).

Outra métrica utilizada foi o reposicionamento do ligante no complexo enzimático. Permitindo a comparação de regiões de aminoácidos no sitio ortostérico com o padrão de interação com os aminoácidos ligados ao ligante cristalográfico. Sendo a função footprint presente no pacote do DOCK 6.7, capaz de realizar e avaliar se os padrões de ligação foram mantidos ( BALIUS et al, 2011).

Através do servidor online PoseView web foi utilizado para gerar imagens referentes as interações do ligante com a estrutura da proteína. (STIERAND, K et al., 2006)

\section{RESULTADOS E/OU DISCUSSÃO}

O programa DOCK 6.7 foi o programa escolhido para realizar esta simulação, varias funções de pontuação estão presentes neste programa, funções capazes de 
combinar diferentes características para mensurar a complementariedade moléculaenzima. Deste modo a função GRID SCORE e FOOTPRINT foram utilizadas neste estudo, aspecto como busca por conformações ideais de ligações e quantificação das energias eletrostáticas são observadas na função GRID SCORE. A função FOOTPRINT emprega identidades moleculares em resíduos com base em interações de van der Waals, interações eletrostáticas ou a soma deles (HOLDEN., et al 2014).

Para determinar a escolha das funções para a triagem virtual foi necessário realizar o processo de avaliação destas funções. Através de duas métricas, pode-se analisar a confiabilidade dos recursos utilizados no processo de acoplamento molecular. O RMSD que tem com um indicativo quando o resultado for menor que $2.0 \AA$ é considerado como bom resultado. A outra métrica é a utilização da função FOOTPRINT (FPS) que analisa a similaridade de ligação entre os aminoácidos dos ligantes no sitio. Sendo considerado que quanto mais próximo este resultado estiver do ligante cristalográfico, significa que essa métrica obteve um resultado de maior confiabilidade.

Figura 1: Representação gráfica da distribuição no espaço físico-químico dos inibidores da KasA.

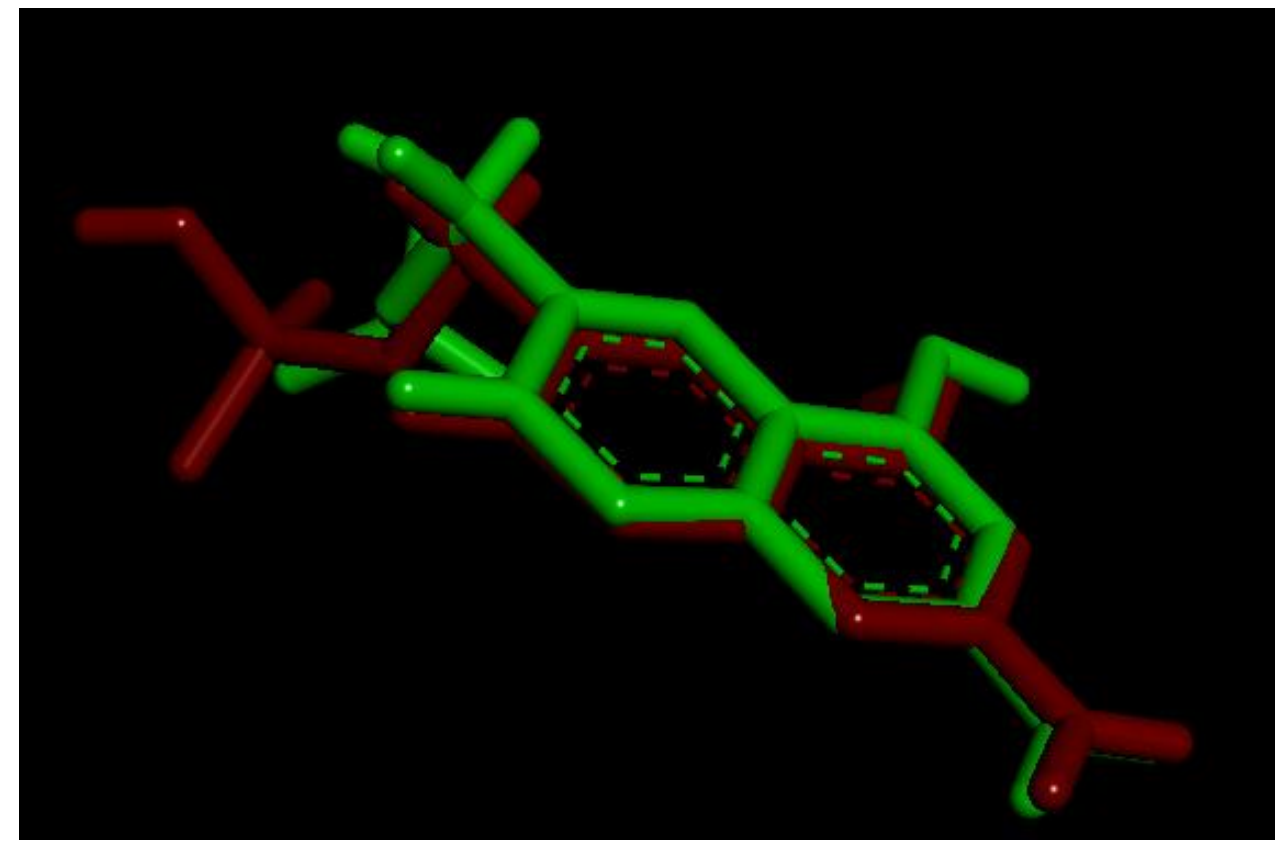

A avaliação do RMSD na figura 1 da capacidade do programa em reposicionar o ligante no espaço da enzima onde se encontra o modelo cristalográfico foi bem sucedida, uma vez que o valor de RMSD obtido foi de $1.01 \AA$.

Como o uso da FPS difere do método DOCK padrão em termos de dois critérios principais: propriedades da pose do ligante e estabilidade da pose do ligante. As propriedades da pose comparadas entre o ligante de referencia e o re-acoplado incluem distribuições de pontuação DOCK e FPS, massa molecular, número de ligações rotativas, eficiência de ligação, carga formal do ligante, sobreposição de volume e comparações de regiões específicas entre compostos ativos e inativos. Sendo os cálculos baseados nas interações de van der walls, eletrostática e a combinação das duas. 
Figura 2. Representação esquemática da sequencia de resíduos baseado nas interações de VDW, sendo cristalográfico (azul) e do re-acoplamento molecular (vermelho).

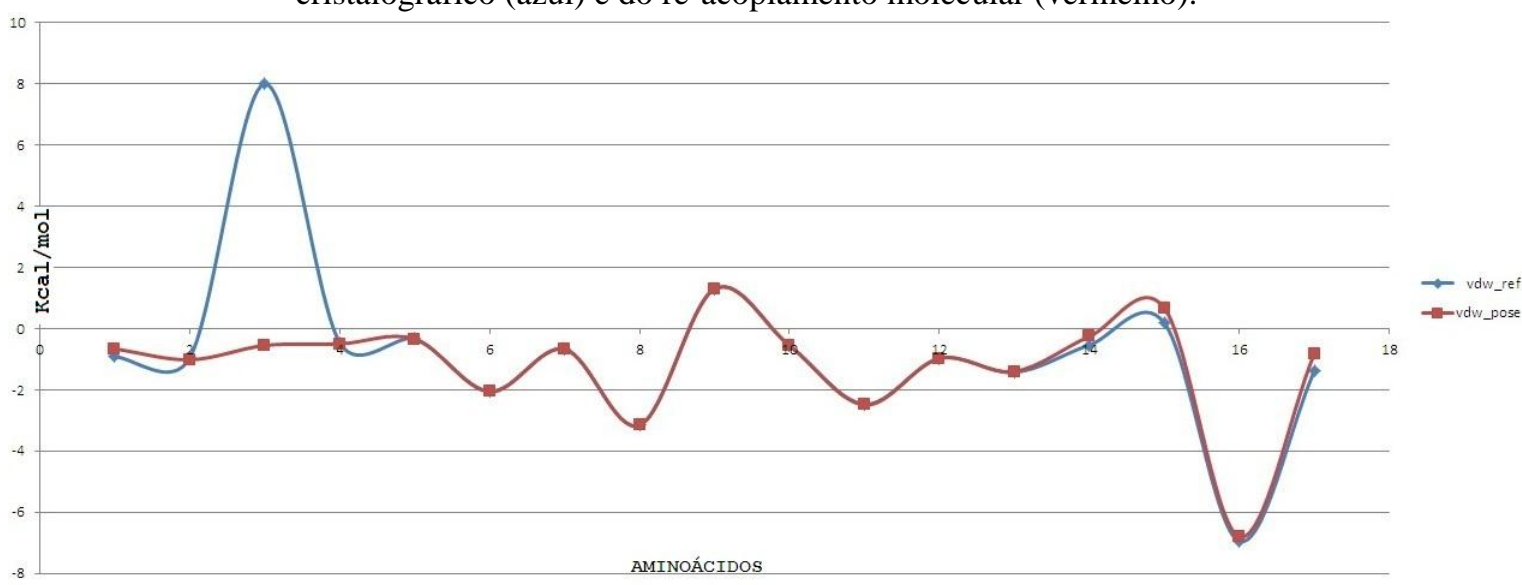

Figura 3. Representação esquemática da sequencia de resíduos baseado nas interações eletrostáticas, sendo cristalográfico (azul) e do re-acoplamento molecular (vermelho).

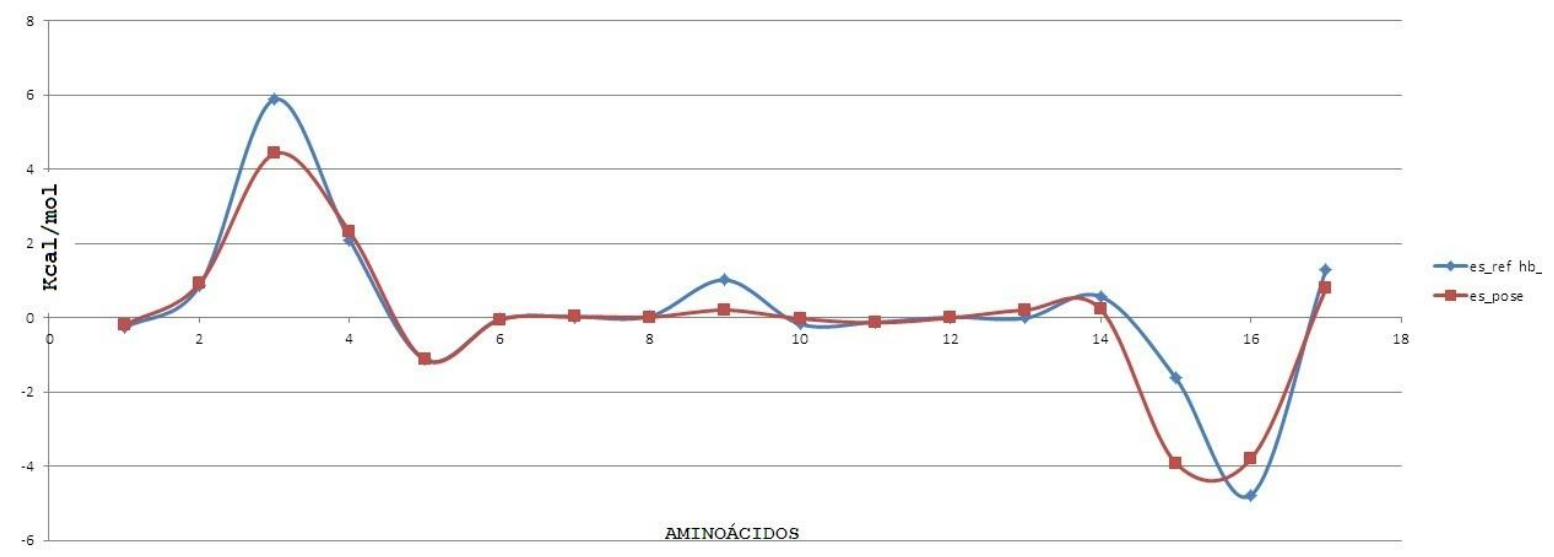

No entanto, com base na comparação das regiões específicas podem indicar quais resíduos tende apontar as regiões ativas e inativas. Na figura 2 o ASP 17 na posição 3 apresentou diferença na energia de van der Waals entre a pose calculada e a obtida do PDB, o restante dos resíduos não apresentou diferenças energéticas. Porém o gráfico das interações intermoleculares eletrostáticas apresentou um maior número de resíduos com diferenças energéticas em relação a pose inicial. Analisando de uma forma mais conclusiva, a similaridade energética entre o ligante cristalográfico e a pose gerada pelo re-coplamento molecular são favoráveis para o reconhecimento molecular, portanto o programa consegue acoplar os compostos em regiões em que os resíduos são ativos.

O servidor online posseview web foi utilizado para gerar imagens referentes as interações do ligante com a estrutura da proteína. Sendo a molécula ZINC000085488243, a melhor estrutura ranqueada do banco BIOGENIC com a função FOOTPRINT obtendo um valor de score igual a $-69,56 \mathrm{Kcal} / \mathrm{mol}$. 
FIGURA 4: Representação Molécula ZINC000085488243 que obtive melhor valor de energia.

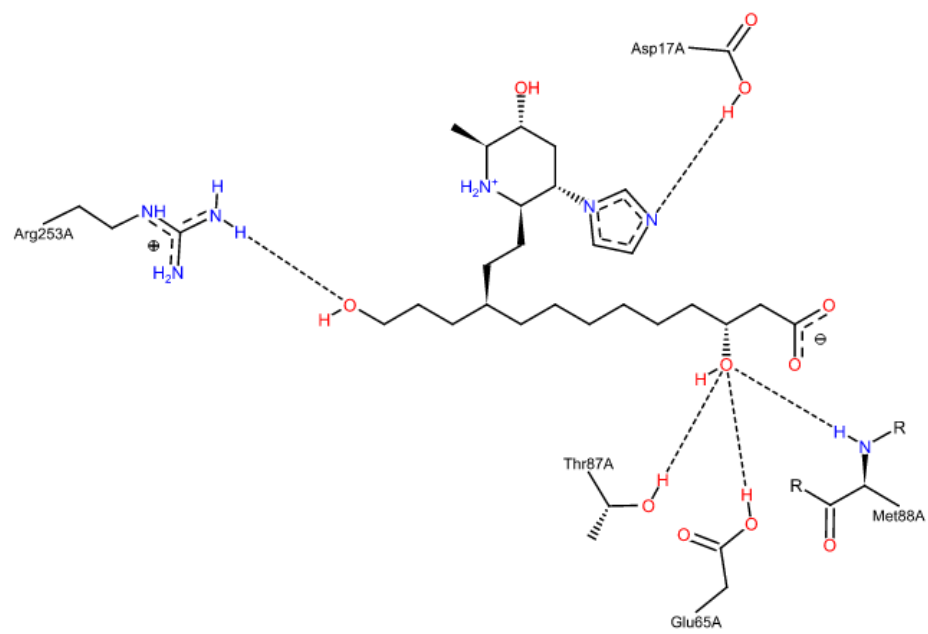

Como se pode observar através da FIGURA 4 ocorre a formação de ligação doadora e receptora de hidrogênio. Sendo mantida e reproduzida a mesma predominância de interação do ligante cristalográfico.

\section{CONSIDERAÇÕES FINAIS}

Através do programa DOCK 6.7 utilizando as funções GRIG SCORE para buscar a melhor conformação e a função FOOTPRINT SCORE para mensurar as energias de interação. Sendo a Molécula ZINC000085488243 a que obteve melhor energia de interação. Desta forma, a molécula pode agora passar por estudo in vitro com um maior potencial de não ser reprovado nestas etapas seguintes. Pode-se também adotar outros estudos in silico visando aumentar o grau de confiabilidade desta estratégia de planejamento racional de novos fármacos.

\section{REFERÊNCIAS}

BALIUS, Trent E., MUKHERJEE, Sudipto; RIZZO, Robert C. Implementation and evaluation of a docking-rescoring method using molecular footprint comparisons. Journal of computational chemistry, v. 32, n. 10, p. 2273-2289, 2011.

BROZELL, Scott R. et al. Evaluation of DOCK 6 as a pose generation and database enrichment tool. Journal of computer-aided molecular design, v. 26, n. 6, p. 749-773, 2012.

IRWIN, J. J. et al. ZINC - A free tool to discover chemistry for biology. Journal of chemical information and modeling, n. 1, p. 1-40, 2012.

EWING, T. J. A. et al. DOCK 4.0: search strategies for automated molecular docking of flexible molecule databases. J. Comput. Aided Mol. Des., v. 15, n. 5, p.411428, maio 2001.

Stierand, K., Maaß, P., Rarey, M. (2006) Molecular Complexes at a Glance: Automated Generation of two-dimensional Complex Diagrams. Bioinformatics, 22, $1710-1716$.

WORLD HEALTH ORGANIZATION et al. Global tuberculosis report 2012. Geneva: WHO; 2015. 